\title{
Impact of Body Mass Index (BMI) and Physical activities among menopausal women
}

\author{
Rahman $\mathrm{MM}^{1 *}$, Rahman $\mathrm{MA}^{1}$, Alo $\mathrm{K}^{2}$, Mehrin $\mathrm{F}^{1}$ \\ ${ }^{I}$ Department of Community Medicine, Anwer Khan Modern Medical College, Dhaka, Bangladesh; \\ ${ }^{2}$ Department of Physiology, Khwaja Yunus Ali Medical College, Enayetpur, Serajganj; Bangladesh
}

\begin{abstract}
Background: The impact of body mass index (BMI) and physical activity on menopausal symptoms is still unclear. The relationship between menopausal symptoms with physical activity and BMI may differ depending on the specific symptom and socio-demographic factors may have impact on the symptoms.

Objectives: It was aimed to determine most common presenting symptoms as per MRS scale, and to assess physical activity status as per IPAQ scale. Also to assess the impact of physical activity and BMI on common menopausal symptoms in addition to socio-demographic characteristics of the respondents in particular.
\end{abstract}

Methods: This was a descriptive cross-sectional study among menopausal women age between 45-60 years attended at Outpatient Department (OPD) of Obs \& Gynae in three randomly selected tertiary care hospital of the country during November 2017 to April 2018. The data were generated as per Menopause Rating Scale (MRS) and by International Physical Activity Questionnaire (IPAQ) and by calculation of Body Mass Index (BMI).

Results: About $70.0 \%$ respondents were within $45-54$ years of age group, $28.0 \%$ respondents were illiterate and $78.0 \%$ were housewife. Overweight was to be found almost $30.0 \%$ within $50-54$ years age group. Respondent's somato-vegetative menopausal symptoms like hot flashes, heart discomfort and sleeping problems were found mild to moderate among 53.0-67.0\% respondents mostly. Psychological and urogenital menopausal symptoms were found mild to moderate among $52-62.0 \%$ and $45-53.0 \%$ respondents respectively. The irritability and heart discomfort were found significantly associated with age. Moreover, joint and muscular discomfort, hot flushes, sweating and heart discomfort were also found significantly associated with BMI $(p<.05)$.

Conclusion: Findings of the study will help planners and policy makers in developing one stop comprehensive services as appropriate in minimizing symptoms without medications and will also help minimizing burden of symptoms among menopausal women towards a comfortable end stage life line towards menopause specific quality of life (MENQOL).

Keywords: Menopause rating scale, International physical activity questionnaire, Body mass index, Obesity

\section{Introduction}

Menopause is a physiological phase that is characterized by the permanent cessation of menstrual periods in women due to loss of ovarian follicular function. ${ }^{1}$ During the menopausal transition, women experience various physical, psychological, and social changes that may affect their quality of life. ${ }^{2}$ Several symptoms, including hot flushes, night sweats, vaginal dryness, depression, irritability, headache, and sleep disturbance, can occur more frequently in this period. ${ }^{3}$ In the Menopause specific Quality of Life (MENQOL) questionnaire, these symptoms are divided into four domains, namely, the physical, vasomotor, psychosocial, and sexual symptom domains. ${ }^{4}$ Hormone replacement therapy can be

*Correspondence: Dr. Md. Mahfuzar Rahman, Department of Community Medicine, Anwer Khan Modern Medical College, Dhaka, Bangladesh; email: mahfuzarrahman26@yahoo.com,ORCID: 0000-0002-6282-7164 used to alleviate menopausal symptoms ${ }^{5}$, but given the possible serious adverse effects of hormone therapy, many women are searching for alternative therapies to reduce their menopausal symptoms. ${ }^{5}$ One such therapy is exercise, which is one of the most commonly used alternatives for menopausal symptoms. ${ }^{5}$ Physical activity is also associated with many health benefits, including a decreased risk of cardiovascular disease, metabolic syndrome, obesity, cancer, osteoporosis, and depression. ${ }^{6}$ There is evidence that regular physical activity may be an effective way of preventing or attenuating menopause-related symptoms. Several previous studies showed that physical activity significantly reduces menopausal symptoms $^{7}$ but other studies have found that physical activity improves general symptoms such as physical and psychosocial symptoms, although it does not influence specific symptoms such as vasomotor and sexual symptoms. ${ }^{8}$ A meta- 
analysis has reported inconsistent results regarding the effect of physical activity on menopausal symptoms, with mixed results being observed for different types of symptoms. ${ }^{9}$ In addition, engaging in habitual physical activity at least 60 minutes/day showed favorable effects on the prevention of menopausal symptoms, and a high total physical activity level was also associated with less climacteric symptoms. ${ }^{10}$ Previous study in multiethnic groups of midlife women showed that the specific types of women's physical activity influenced the prevalence and severity of menopausal symptoms, which was differed by ethnicity. ${ }^{11}$ There are conflicting results related to the effects of body mass index on menopausal symptoms, especially hot flushes. Body weight is primarily regulated by a series of physiological process but is also influenced by external societal and cognitive factors. ${ }^{12}$ Several studies showed that BMI is the main determinant of endogenous estrogen levels. In addition, it appears that estradiol (E1) and estrone (E2) are at higher levels among obese women than women within the normal range. Some studies demonstrate the fact that fewer vasomotor symptoms occur in obese women as compared to non-obese women. ${ }^{13}$ In contrast, in other study E1 and E2 levels decrease earlier in obese women as compared to non-obese women. Menopause can lead to a wide range of symptoms including hot flashes, night sweats, sleeping problems, emotional and cognitive symptoms, irritability, anxiety, vaginal itching and dryness, and urinary symptoms. Reported hot flushes rates for peri-menopausal women ranged from 40 to $60 \% .{ }^{14}$ The prevalence of vaginal atrophy in the early stages of the menopause increases as a woman advances through the postmenopausal years. ${ }^{15}$ In a study conducted by Khan BEZ, Rahman AM, Begum N et al among urban post menopausal women revealed that the most prevalent menopausal symptoms were joint $\&$ muscular pain, anxiety and sleep disturbance, chest discomfort as well as physical and mental exhaustion were among $90.1 \%, 80.3 \%$, and $78.9 \%$ respectively. ${ }^{16}$ The study also revealed relationship between BMI and hot flash was statistically significant $(p<0.001)$. Urogenital symptoms and depression were also found to be statistically significant in relation with history of chronic disease.${ }^{17}$ Moreover, proportion of sleep problems, physical and mental exhaustion, bladder problems (urinary incontinence), joint \& muscular discomfort were more in inactive than minimally active but the relationship were not statistically significant $(p>0.05)$. This result indicates that physical activities may have some role in reducing menopausal symptoms.${ }^{17}$ In addition, with regard to recent evidence, the impact of body mass index (BMI) and physical activity on menopausal symptoms is still unclear. The relationship between menopausal symptoms with physical activity and BMI may differ depending on the specific symptom and socio-demographic factors may have impact on the symptoms. Most studies of menopause to date have been based either on Euro-American populations or far away from Bangladesh. So far, the impact of physical activity and body mass index on menopausal symptoms and associated socio-demographic characteristics has not been studied in Bangladesh. Therefore, the objective of this study was to determine the impact of physical activity and BMI on menopausal symptoms among Bangladeshi women in addition to socio-demographic factors.

\section{Material and Methods}

It was a descriptive cross-sectional study in a randomly selected three tertiary care hospitals. The respondents were menopausal women between the ages of 45-60 years attended at the Gynae \& Obs OPD of tertiary care hospitals in three randomly selected divisions; Dhaka,(SSMCH) Sylhet MAG Osmani MCH and Rajshahi SZRMCH. The criteria for selection of respondents were included as women of postmenopausal (no more menses in the last 12 months) who are willing and able to respond. However, women having pregnancy or breastfeeding, hysterectomy with intact ovary, chronic irregular menstruation, use of hormonal medication in the last 3 months or the inability to complete the questionnaire were excluded as respondents. The periods of study were of six months from November 2017 to April 2018. The data were generated as per MRS and IPAQ duly pre-tested and by calculation of BMI. The total sample size was 390 (130 in each division) as per sample size formula according to Cochran's and respondents were selected conveniently as per inclusion and exclusion criteria. Ethical issues were dealt using written informed consent form duly signed by respondents covering privacy and confidentiality of information in addition to matter of withdrawal at any point of time. Ethical clearance was taken from BMRC ethical review board as its regular process for funding. The study also involved measurement of weight and height for calculating BMI status. After collection, data were cleaned, complied, edited and analyzed manually and also by using appropriate computer software and presented by tables and diagrams as appropriate. 


\section{Results}

Table I: Age and BMI status of the respondents $(n=390)$

\begin{tabular}{|c|c|c|c|c|c|}
\hline $\begin{array}{l}\text { Age in } \\
\text { years }\end{array}$ & $\begin{array}{c}\text { Under } \\
\text { wt. } \\
<18.5\end{array}$ & $\begin{array}{c}\text { Normal } \\
\text { wt. } \\
\text { 18.5- } \\
24.9\end{array}$ & $\begin{array}{c}\text { BMI } \\
\text { Over } \\
\text { wt. } \\
25.0- \\
29.9\end{array}$ & $\begin{array}{c}\text { Class I } \\
\text { Obes. } \\
\text { 30.0- } \\
34.9\end{array}$ & $\begin{array}{c}\text { Class } \\
\text { II } \\
\text { Obes. } \\
\text { 35.0- } \\
39.9\end{array}$ \\
\hline $\begin{array}{l}45-49 \\
n=140\end{array}$ & 00 & $\begin{array}{c}95 \\
(67.85)\end{array}$ & $\begin{array}{c}42 \\
(30.00)\end{array}$ & $\begin{array}{c}03 \\
(2.15)\end{array}$ & 00 \\
\hline $\begin{array}{l}50-54 \\
n=133\end{array}$ & $\begin{array}{c}05 \\
(3.76)\end{array}$ & $\begin{array}{c}86 \\
(64.66)\end{array}$ & $\begin{array}{c}39 \\
(29.33)\end{array}$ & $\begin{array}{c}03 \\
(2.25)\end{array}$ & 00 \\
\hline $\begin{array}{l}55-59 \\
n=57\end{array}$ & $\begin{array}{c}03 \\
(5.27)\end{array}$ & $\begin{array}{c}33 \\
(57.89)\end{array}$ & $\begin{array}{c}14 \\
(24.56)\end{array}$ & $\begin{array}{c}07 \\
(12.28)\end{array}$ & 00 \\
\hline $\begin{array}{l}60+ \\
n=60\end{array}$ & 00 & $\begin{array}{c}39 \\
(65.00)\end{array}$ & $\begin{array}{c}21 \\
(35.00)\end{array}$ & 00 & 00 \\
\hline
\end{tabular}

Mean age: 52.47 years SD: \pm 5.27 . About $70 \%$ respondents were within 45-54 years of age group.

N:B: Figures in the parenthesis indicate percentages

Overweight was found almost $30.0 \%$ within $50-54$ years of age. However, class I obesity was within the age of 55-59 years. None was found as class II obesity. The age in any group found no significance with BMI (table II).

Table II: National status based on BMI $(\mathrm{n}=390)$

\begin{tabular}{|c|c|c|c|c|c|}
\hline \multirow[t]{2}{*}{ BMI group } & \multicolumn{5}{|c|}{ Age group } \\
\hline & $\begin{array}{c}45-49 \\
(n=140)\end{array}$ & $\begin{array}{c}50-54 \\
(n=133)\end{array}$ & $\begin{array}{c}55-59 \\
(n=57)\end{array}$ & $\begin{array}{c}>60 \\
(n=60)\end{array}$ & $p$-value \\
\hline Under weight $(<18.5)$ & 00 & $18.23 \pm 0.5$ & $17.21 \pm 0.3$ & $17.20 \pm 0.2$ & 0.544 \\
\hline Normal weight(18.5-24.9) & $23.56 \pm 3.3$ & $23.43 \pm 3.2$ & $22.43 \pm 3.12$ & $21.43 \pm 2.1$ & 0.884 \\
\hline Over weight(25.0-29.9) & $28.23 \pm 3.3$ & $28.22 \pm 3.2$ & $26.22 \pm 2.1$ & $26.22 \pm 3.2$ & 0.718 \\
\hline Class I Obese(30.0-34.9) & $33.5 \pm 2.1$ & $33.5 \pm 3.1$ & $32.00 \pm 2.1$ & 00 & 0.681 \\
\hline Class II Obese(35.0-39.9) & 00 & 00 & 00 & 00 & ------- \\
\hline \multicolumn{6}{|c|}{$N: B$ : Age in any group found no significance with BMI } \\
\hline \\
\hline \multicolumn{6}{|l|}{150} \\
\hline \multicolumn{6}{|l|}{100} \\
\hline \multicolumn{6}{|l|}{50} \\
\hline \multicolumn{6}{|l|}{ Somatic symptoms } \\
\hline $\begin{array}{l}\text {-Hot flash, sweating } \\
\text {-Heart discomfort } \\
\text {-Sleep problems }\end{array}$ & $\begin{array}{l}\text {-Depressive mood } \\
\text {-Irritibility } \\
\text {-Anxiety }\end{array}$ & & $\begin{array}{l}\text {-Sexual proble } \\
\text {-Bladder prob }\end{array}$ & & \\
\hline
\end{tabular}

Figure1: Menopausal symptoms as per MRS sub-scale (Somato-vegetative, Psychological and Urogenital)

Table III: Association of MRS symptoms by selected sociodemographic characteristic and BMI

\begin{tabular}{|c|c|c|c|c|}
\hline Symptoms & Age & $\begin{array}{l}\text { Marital } \\
\text { status }\end{array}$ & $\begin{array}{l}\text { Monthly } \\
\text { income }\end{array}$ & BMI \\
\hline $\begin{array}{l}\text { Joint and } \\
\text { muscular } \\
\text { discomfort }\end{array}$ & 0.463 & 0.528 & 0.615 & $0.021^{*}$ \\
\hline $\begin{array}{l}\text { Physical \& } \\
\text { mental } \\
\text { exhaustion }\end{array}$ & 0.552 & 0.527 & 0.266 & 0.386 \\
\hline Irritability & $0.048^{*}$ & 0.073 & 0.401 & 0.756 \\
\hline $\begin{array}{l}\text { Hot flushes } \\
\text { \& sweating }\end{array}$ & 0.966 & 0.369 & 0.697 & $0.001^{*}$ \\
\hline $\begin{array}{l}\text { Sleep } \\
\text { problems }\end{array}$ & 0.586 & 0.424 & $0.025^{*}$ & 0.683 \\
\hline Anxiety & 0.585 & 0.712 & 0.154 & 0.958 \\
\hline $\begin{array}{l}\text { Depressive } \\
\text { mood }\end{array}$ & 0.141 & 0.406 & 0.153 & 0.681 \\
\hline Heart & $0.003^{*}$ & 0.541 & 0.623 & $0.001^{*}$ \\
\hline
\end{tabular}

\begin{tabular}{lcccc}
\hline $\begin{array}{l}\text { discomfort } \\
\text { Vaginal } \\
\text { dryness }\end{array}$ & 0.065 & 0.672 & 0.739 & 0.541 \\
$\begin{array}{l}\text { Sexual } \\
\text { problems }\end{array}$ & 0.032 & 0.052 & $0.038^{*}$ & 0.931 \\
$\begin{array}{l}\text { Bladder } \\
\text { problems }\end{array}$ & 0.276 & 0.712 & 0.379 & 0.683 \\
\hline
\end{tabular}

*Value indicates significant association

The symptoms irritability and heart discomfort were found significantly associated with age. On the other hand, sleep and sexual problem were found significantly associated with monthly income. Moreover, joint and muscular discomfort, hot flushes and sweating including heart discomfort were also found significantly associated with BMI $(p<.05)$. 
Table IV: MRS Symptoms by IPAQ physical activity level

\begin{tabular}{|c|c|c|c|}
\hline \multirow{2}{*}{ MRS symptoms } & \multicolumn{3}{|c|}{ Physical activity level } \\
\hline & Low & Moderate & High \\
\hline \multicolumn{4}{|l|}{ Somato-vegetative } \\
\hline $\begin{array}{l}\text { Hot flushes, } \\
\text { sweating } \\
n=234\end{array}$ & $\begin{array}{c}140 \\
(59.82)\end{array}$ & $\begin{array}{c}81 \\
(34.62)\end{array}$ & $\begin{array}{c}13 \\
(5.56)\end{array}$ \\
\hline $\begin{array}{l}\text { Heart discomfort } \\
\mathrm{n}=286\end{array}$ & $\begin{array}{c}165 \\
(57.69)\end{array}$ & $\begin{array}{c}96 \\
(33.57)\end{array}$ & $\begin{array}{c}25 \\
(8.74)\end{array}$ \\
\hline $\begin{array}{l}\text { Sleep problems } \\
\mathrm{n}=307\end{array}$ & $\begin{array}{c}206 \\
(67.10)\end{array}$ & $\begin{array}{c}78 \\
(25.40)\end{array}$ & $\begin{array}{c}23 \\
(7.50)\end{array}$ \\
\hline $\begin{array}{l}\text { Joint and muscular } \\
\text { discomfort } \mathrm{n}=330 \\
\text { Psychological }\end{array}$ & $\begin{array}{c}188 \\
(56.97)\end{array}$ & $\begin{array}{c}112 \\
(33.94)\end{array}$ & $\begin{array}{c}30 \\
(9.09)\end{array}$ \\
\hline $\begin{array}{l}\text { Depressivemood } \\
\mathrm{n}=268\end{array}$ & $\begin{array}{c}155 \\
(57.84)\end{array}$ & $\begin{array}{c}88 \\
(32.83)\end{array}$ & $\begin{array}{c}25 \\
(9.33))\end{array}$ \\
\hline $\begin{array}{l}\text { Irritability } \\
n=283\end{array}$ & $\begin{array}{c}167 \\
(59.01)\end{array}$ & $\begin{array}{c}89 \\
(31.45)\end{array}$ & $\begin{array}{c}27 \\
(9.54)\end{array}$ \\
\hline $\begin{array}{l}\text { Anxiety } \\
\mathrm{n}=291\end{array}$ & $\begin{array}{c}145 \\
(49.83)\end{array}$ & $\begin{array}{c}125 \\
(42.95)\end{array}$ & $\begin{array}{c}21 \\
(7.22)\end{array}$ \\
\hline $\begin{array}{l}\text { Physical and } \\
\text { mental exhaustion } \\
n=291\end{array}$ & $\begin{array}{c}168 \\
(57.73)\end{array}$ & $\begin{array}{c}107 \\
(36.77)\end{array}$ & $\begin{array}{c}16 \\
(5.50)\end{array}$ \\
\hline \multicolumn{4}{|l|}{ Urogenital } \\
\hline $\begin{array}{l}\text { Sexual problems } \\
n=250\end{array}$ & $\begin{array}{c}136 \\
(54.40)\end{array}$ & $\begin{array}{c}104 \\
(41.60)\end{array}$ & $\begin{array}{c}10 \\
(4.00)\end{array}$ \\
\hline $\begin{array}{l}\text { Bladder problems } \\
\mathrm{n}=257\end{array}$ & $\begin{array}{c}138 \\
(57.70)\end{array}$ & $\begin{array}{c}92 \\
(35.80)\end{array}$ & $\begin{array}{c}27 \\
(10.50)\end{array}$ \\
\hline $\begin{array}{l}\text { Dryness of vagina } \\
n=244\end{array}$ & $\begin{array}{c}129 \\
(52.87)\end{array}$ & $\begin{array}{c}108 \\
(44.26)\end{array}$ & $\begin{array}{c}07 \\
(2.87)\end{array}$ \\
\hline
\end{tabular}

$\mathrm{N}: \mathrm{B}$ : MRS symptoms mostly predominant within low and moderate physical activity level (table IV).

Table V: Association of MRS symptoms by physical activity level

\begin{tabular}{lccc}
\hline MRS Symptoms & \multicolumn{3}{c}{ Physical activity level } \\
\cline { 2 - 4 } & Low & Moderate & High \\
\hline Somato-vegetative & & & \\
Hot flushes, sweating & 0.463 & 0.528 & $0.015^{*}$ \\
Heart discomfort & 0.552 & 0.527 & $0.016^{*}$ \\
Sleep problems & $0.048^{*}$ & 0.073 & 0.401 \\
Joint and muscular & $0.036^{*}$ & 0.369 & 0.697 \\
discomfort & & & \\
Psychological & & & \\
Depressive mood & 0.003 & $0.424^{*}$ & 0.645 \\
Irritability & 0.585 & 0.712 & 0.154 \\
Anxiety & 0.141 & 0.406 & 0.153 \\
Physical and mental & 0.586 & 0.541 & 0.623 \\
exhaustion & & & \\
Urogenital & & & 0.739 \\
Sexual problems & $0.002^{*}$ & 0.672 & 0.674 \\
Bladder problems & 0.563 & 0.052 & 0.379 \\
Dryness of vagina & 0.276 & 0.712 & \\
\hline
\end{tabular}

- Indicates statistically significant p value

Low physical activity was to be found significantly associated with symptoms like; sleep problems, and joint and muscular discomfort and sexual problems $(p=<0.05)$. On the other hand, moderate physical activity was also found associated with psychological symptoms like; depressive mood. However, high physical activity was to be found associated with symptoms like; hot flushes, sweating and heart discomfort as well $(p=<0.05)$.

\section{Discussion}

In this study the age in any group found no significance with BMI. Menopause is a physiological phase that is characterized by the permanent cessation of menstrual periods in women. During the menopausal transition, women experience various physical, psychological, and social changes that may affect their quality of life. ${ }^{2}$ Physical activity is associated with decreased risk of cardiovascular disease, metabolic syndrome, obesity, cancer, osteoporosis, and depression. ${ }^{6}$ There is evidence that regular physical activity may be an effective way of preventing menopauserelated symptoms. In this study respondent's somato-vegetative menopausal symptoms like; hot flashes, heart discomfort, and sleeping problems were found mild to moderate among 53-67\% respondents. Psychological menopausal symptoms like; depressive mood, irritability, anxiety, and physical and mental exhaustion were found mild to moderate among $52-60 \%$ respondents approximately. Urogenital menopausal symptoms like; sexual problem, bladder problem, dryness of vagina, joint and muscular discomfort were found mild to moderate among $45-52 \%$ respondents approximately. Several previous studies showed that physical activity significantly reduces menopausal symptoms ${ }^{8}$ but other studies have found that physical activity improves general symptoms such as physical and psychosocial symptoms, although it does not influence specific symptoms such as vasomotor and sexual symptoms. ${ }^{7,8}$ In addition, engaging in habitual physical activity at least 60 minutes/day showed favorable effects on the prevention of menopausal symptoms, and a high total physical activity level was also associated with less climacteric symptoms..$^{10}$ There are conflicting results related to the effects of body mass index on menopausal symptoms, especially hot flushes. Several studies showed that BMI is the main determinant of endogenous estrogen levels. Some studies demonstrate the fact that fewer vasomotor symptoms occur in obese women as compared to non-obese women. ${ }^{13}$ This study revealed the symptoms like; irritability and heart discomfort were found significantly associated with age. On the other hand, sleep and sexual problem were found significantly associated with monthly income. Moreover, joint and muscular discomfort, hot flushes and sweating including heart discomfort were also found significantly associated with BMI. However, marital status was to be found no association with any of those 
symptoms. In addition, with regard to recent evidence, the impact of body mass index (BMI) and physical activity on menopausal symptoms is still unclear. However, study conducted among urban postmenopausal women in Bangladesh also revealed symptoms were mostly of joint and muscular pain, anxiety, and sleep disturbance, chest discomfort as well as physical and mental exhaustion in addition to problem as well. ${ }^{18}$

\section{Conclusion}

Study respondents had the somato-vegetative menopausal symptoms like; hot flashes, heart discomfort, and sleeping problems were found mild to moderate among 53.0-67.0\% respondents. Psychological menopausal symptoms like; depressive mood, irritability, anxiety and physical and mental exhaustion were found mild to moderate among $52.0-60.0 \%$ in addition to urogenital symptoms among $45.0-52.0 \%$ and those were of mild to moderate in nature. Although the selected respondents were the part of population, however a large-scale study in addressing those issues would have been considered to evaluate the health and wellbeing of menopausal women in this country. Thus, it would help evaluating the situation by the policymakers in developing strategies towards its prevention by early detection of the problems for this particular segment of women population.

\section{Acknowledgement}

The authors are gratefully acknowledge the funding by the Bangladesh Medical Research Council (BMRC). Our sincere thanks to the study population for their active participation as well as the support staff involved in this study.

Conflict of interest: The authors had no conflict of interest.

Funding: Bangladesh Medical Research Council (BMRC)

Ethical approval: National Ethics Review Committee of BMRC

Submitted: 01 ${ }^{\text {st }}$ March, 2020

Final revision received: $18^{\text {th }}$ March, 2020

Accepted: $19^{\text {th }}$ March, 2020

Published: $1^{\text {st }}$ August, 2020

\section{References}

1. Greendale GA, Lee NP, Arriola ER: The menopause. Lancet 1999; 13: 571-80.

DOI:10.4236/ojn.2014.48063

2. Kumari M, Stafford M, Marmot M: The menopausal transition was associated in a prospective study with decreased health functioning in women who report menopausal symptoms, J Clin Epidemiol 2005; 58: 719-27

DOI:10.1016/j.jclinepi.2004.09.016
3. Li S, Holm K, Gulanick M, Lanuza D, Penckofer S: The relationship between physical activity \& perimenopause. Health care Women Int 1999; 20: 163-78.

DOI:10.1080/073993399245863

4. Zollner YF, Acquadro C, Schaefer M: Literature review of instruments to assess health-related quality of life during \& after menopause. Qual life Res 2005; 14: 309-27.

5. Daley A, MacArthur C, McManus R, StokesLampard H, Wilson S Roalfe A, MutrieN: Factors associated with the use of complementary medicine \& non-pharmalogicalinterventions in symptomatic menopausal women. Climacteric 2006; 9: 336-46.

DOI: $10.1080 / 13697130600864074$

6. Physical activity Guidelines Advisory committee: Physical Activity Guidelines Advisory Committee Report, Washington, DC: U. S. Department of Health \& Health Services. 2008

7. Gold EB, Sternfeld B, Kelsey JL, Brown C, Mouton C, ReameN, Salamone L, StellatoR: Relation of demographic \& lifestyle factors to symptoms in a multi-racial/ethnic population of women 40-55 years of age. Am J Epidemiol. 2000; 152: 463-73.

DOI:10.1093/aje/152.5.463

8. McAndrew LM, Napolitano MA,Albrecht A, Farrell NC, Marcus BH, Whiteley JA: When, Why $\&$ for whom there is relationship between physical activity \& menopause symptoms.Maturitas. 2009; 64:119-25

DOI:10.1016/j.maturitas.2009.08.009.

9. Sternfeld B, Dugan S: Physical activity \& health during the menopausal transition. ObstetGynecol Clin North Am. 2011; 38: 537-66

DOI: $10.1016 /$ j.ogc.2011.05.008

10. De Azevedo Guimaraes AC, Baptista F: influence of habitual physical activity on the symptoms of climacterium/menopause \& the quality of life middle-aged women. Int J Womens Health. 2011; 3:319-28

\section{DOI: 10.2147/IJWH.S24822}

11. Chang SJ, Chee W, ImEO: Menopausal symptoms \& physical ativity in multi-ethnic groups of midlife women: a secondary analysis J Adv Nurs. 2013; 69:1953-65.

\section{DOI: $10.1111 /$ jan. 12056}

12. Rahman SMM, Kabir I, Bhuyan MAH, Akter BMD, Hossain SM. Prevalence and determinants of childhood obesity in Dhaka city. Bangladesh Med Res Counc Bull. 2019; 45: 68-80.

13. Mirzaiinjmabadi K, Anderson D, Barnes M; The relationship between exercise, body mass index \& menopausal symptoms in midlife Australian women. Int J Nurs Pract. 2006; 12:28-34.

DOI:10.1111/j.1440-172X.2006.00547.x 
14. Klinga $\mathrm{K}$, van Holst $\mathrm{T}$, Runnebaum B: Influence of severe obesity on peripheral hormne concentration in pre \& post menopausal women, Eur $\mathbf{J}$ obstet Gynecol Reprod Biol. 1943; 15: 103-12.

DOI: $10.1016 / 0028-2243(83) 90178-8$

15. Freeman EW, Sherif K: Prevalence of hot flushes \& night sweats around the world: a systemic review: Climacteric. 2007; 10: 197-214.

DOI:10.1080/13697130601181486
16. Kokot-Kierepa M, Bartuzi A, Kulik-RechbergerT: Local estrogen therapy-clinical implications-2012 update: Ginekol pol. 2012; 43: 772-77.

17. Khan BEZ, Rahman AM, Begum N et.al; Physical activity \& menopausal symptoms Bangladesh Med. 2018; 47: 11-17.

DOI: 10.3329/bmj.v47i1.42818 